\title{
Teaching maxi- and minicomputer programming at the same time: Is there an advantage?
}

\author{
GERRIT E. DeYOUNG, DONALD I. TEPAS, and EDWARD I. CLEMMER \\ St. Louis University, St. Louis, Missouri 63103
}

\begin{abstract}
A course is described that provides concurrent and equal coverage of maxi- and minicomputer systems. The results of student evaluations are provided.
\end{abstract}

Courses in introductory computer programming for psychologists have typically emphasized either minicomputer or maxicomputer programming. Goode (1972) discussed a graduate level introductory course in the minicomputer for research laboratory control in FOCAL and assembly language. Bailey (1973) discussed an introductory course emphasizing maxicomputer FORTRAN programming with a 2 -week introduction to real time on-line computers, to be followed by specialized courses in either system. Gregg (1973) discussed a graduate level course emphasizing computer simulation with the maxicomputer and the use of Carnegie-Mellon's minicomputer for research laboratory control (this course required previous programming experience).

\section{RATIONALE}

Concurrent and equal coverage of both maxi- and minicomputer systems in the same course is the strategy used in the Psychology Department at St. Louis University. The reasoning is the following: (1) Similarities in types of instruction classes, such as arithmetic and transfer instructions, allow maximum positive transfer in learning both types of programming at the same time; (2) learning two systems and languages at the same time familiarizes the student with the elements of computer hard-and software which should be constant and those elements which should differ in transferring skills to other systems and applications; thus, maximum generalizability of skills should occur; (3) some degree of specialization in one system is allowed within an introductory course, since optional programming assignments can be made available in each system; (4) as a practical consideration, concurrent use of both systems allows a great deal of turnaround time during periods of peak computer use; (5) since some students may already have experience with one system, such a course provides a good way to review and refresh old skills and extend them on local equipment. On the other hand, we recognized that becoming familiar with two systems at the same time could lead to temporary negative transfer and that some students might find it necessary to sacrifice depth of skills in exchange for learning both systems.

\section{THE COURSE}

The course is organized so as to incorporate as many of the potential advantages as possible. Students are introduced in the first 2 weeks to principles of computer hardware, peripherals, and software, including programming languages and elements shared by most computer systems, such as the binary number system. This section begins with a brief history of computer technology and a discussion of process circuitry and of system configurations. Also included here is a discussion of types of instructions common to most programming. Twelve weeks are devoted to programming, with one $1 \frac{1}{2}-h$ session each week dedicated to each computer. Each week, students are assigned programming exercises for both the PDP-8 and CDC-3300. Initial assignments include programs involving arithmetic operations and expressions in FOCAL and FORTRAN; sort programs are later assigned in both languages. Other exercises include storage manipulation and Teletype output problems using the PAL III assembly language, and data transformation and statistical programs in FORTRAN. The programming section of the course ends with a discussion of the use of canned programs and subroutines.

In the final weeks, out of class time is spent on a final mini- or maxiprogramming project chosen by each student from a number of options; class time is devoted to critical analysis of computer applications, including stimulus generation, game playing, artificial intelligence and simulation, using published literature as points of departure. Enrollment in the course includes students with programming experience as well as students without previous experience. Only graduate students have been enrolled in the course which is taught as a nonrequired course with no fixed prerequisites.

\section{RESULTS AND DISCUSSION}

Anonymous evaluations were obtained from the students. The following tentative conclusions were drawn. Eighty percent of the students experienced moderate positive transfer between systems. In ranking the desirability of various course structures for future offerings, students on the average ranked integrated 
courses as slightly more desirable than independently taught mini- and maxicomputer courses. Students with no previous programming experience showed a substantially lower preference for the concurrent teaching of mini- and maxicomputer programming than did those with experience. Under either structure, students preferred a two-semester to a one-semester course, however. This apparently was caused by a desire to acquire deeper skills with each computer system, regardless of course structure. Seventy percent of the students described the work load as "just right." The other $30 \%$ of the students described the work load as too heavy. All students responding said that they would take the course over again, knowing what they knew about the course after taking it. It should be emphasized that these are preliminary evaluations. Some of the potential advantages would not be apparent until the student attempted to transfer his skills to other systems, for example.

\section{REFERENCES}

Bailey, D. E. Computer training in psychology at the University of Colorado. Behavior Research Methods \& Instrumentation, 1973, 5, 189-191.

Goode, F. M. Training mathematical psychology students in the use of a laboratory computer. Behavior Research Methods \& Instrumentation, 1972, 4, 96-97.

Gregg, L. W. A course of formal instruction in on-line computing at Carnegie-Mellon University. Behavior Research Methods \& Instrumentation, 1973, 5, 184-185. 